\title{
Viewpoint: Needed research on domestic and recreational livestock in wilderness
}

\author{
DAVID N. COLE
}

The Wilderness Act of 1964 (Public Law 88-577) established a system of wilderness areas to be managed in such a way that "natural conditions" are preserved. The acreage that has been designated as wilderness has increased greatly since 1964 to its present size of almost 90 millions acres. Although more than one-half of this acreage is in Alaska, about $1.7 \%$ of the conterminous United States is wilderness and the system is still expanding.

Legislation clearly permits a number of uses that conflict with the strict nature preservation goals of wilderness. Recreational use, perhaps the most generally accepted use of wilderness, inevitably disturbs vegetation, soil, wildlife, and water. Although much of this disturbance is caused by the trampling of human feet, recreational pack and saddle stock are generally more disruptive and cause certain unique types of disturbance. Relatively little is known about the nature and severity of impacts caused by recreational stock or about effective means of managing such impacts short of drastically restricting use.

Another controversial use of wilderness is grazing of domestic livestock. Legislation is explicit about such use. Where livestock grazing occurred prior to an area's designation as wilderness, the Wilderness Act states that it "shall be permitted to continue subject to such reasonable regulations as are deemed necessary by the Secretary of Agriculture." Confusion over the definition of "reasonable regulations" led Congress to develop guidelines for grazing that were included in the Colorado Wilderness Act of 1980 (Public Law 96-560) and subsequent bills establishing Forest Service and Bureau of Land Management wilderness. The critical paragraph states:

\begin{abstract}
There will be no curtailments of grazing in wilderness areas simply because an area is, or has been designated as wilderness, nor should wilderness designations be used as an excuse by administrators to slowly "phase out" grazing. Any adjustments in the numbers of livestock permitted to graze in wilderness areas should be made as a result of revisions in the normal grazing and land management planning and policy setting process, giving consideration to legal mandates, range condition, and the protection of the range resource from deterioration.
\end{abstract}

Further, Congress stated that numbers of livestock are expected to remain close to current levels and that the maintenance and replacement of existing facilities (for example, fences, line cabins, water wells and lines, stock tanks) is permitted, as is occasional use of motorized vehicles for maintenance or emergency purposes. Clearly, Congress intends for domestic livestock grazing to continue in wilderness; the challenge is to accommodate this use with minimal compromise of wilderness preservation values.

The issue of domestic livestock grazing will become more controversial as wilderness areas managed by the Bureau of Land Management are added to the system. Many of these areas are likely to have little recreational use, leaving livestock grazing as the most serious potential threat to wilderness values.

My intent is to point out the importance of problems related to livestock in wilderness and to suggest some particularly critical research needs. I will discuss recreational and domestic livestock separately, in each case giving a brief overview of existing know-

Author is research biologist, Intermountain Research Station, Forest Service, U.S. Department of Agriculture, Ogden, Utah 84401, located at Forestry Sciences Laboratory, P.O. Box 8089, Missoula, Mont. 59807.

Manuscript accepted 6 September 1988. ledge followed by my view of important research topics and some possible research approaches.

\section{Recreational Stock in Wilderness}

Many of the impacts of recreational stock are similar to those caused by hikers, except that they are more pronounced and occur more rapidly. For example, in one experimental study, trails produced by 1,000 horse passes were 2 to 3 times as wide and 1.5 to 7 times as deep as trails produced by 1,000 hiker passes (Weaver and Dale 1978). Bulk density of soils on horse trails increased 1.5 to 2 times as rapidly as on hiker trails. One-half of the vegetation cover was lost after 1,000 hiker passes and 600 horse passes in a grassland and after $\mathbf{3 0 0}$ hiker passes and only $\mathbf{5 0}$ horse passes in a forest. Other studies have found that while hiker use tends to stabilize trail surfaces, horse use loosens the soil, making it more prone to erosion (Whittaker 1978). McQuaid-Cook (1978) suggested that it is this tendency for shod hooves to loosen soil that leads to the more pronounced incision of equestrian trials documented by Dale and Weaver (1974).

Quantitative differences in impact caused by stock parties are also evident on campsites. In the Bob Marshall Wilderness, Montana, stock sites were 6 times as large as backpacker sites. They had more than 4 times the devegetated area, 11 times as many damaged trees, and 25 times as many trees with exposed roots. Stock sites had lost more of their organic horizons, were more compacted, had slower infiltration rates, and had been more extensively invaded by exotic plants (Cole 1983). These differences reflect both the greater trampling force of horse hooves and the impacts caused by confinement of horses. They also reflect behavioral characteristics of horse parties that tend to result in more impact. Compared to backpackers, parties traveling with horses are larger and stay longer; they are more likely to use a wood fire and to visit during the fall (Lucas 1985).

Although our understanding of recreational stock impacts on trails and campsites is incomplete, it is our understanding of impacts in grazing areas where stock are allowed to graze and stay overnight that is most fragmentary. Most of what is known about impacts in such places comes from range management studies outside of wilderness, usually involving animals other than horses and mules and with management objectives that place little importance on preservation of natural conditions. Where range conditions have been studied in wilderness, it has been difficult to isolate the effect of recreational use because it has been superimposed on the effects of earlier or, in many cases, ongoing grazing by domestic livestock (DeBenedetti and Parsons 1979).

Knowledge from other sources and informal observations in wilderness suggest some obvious problems caused by the grazing and confinement of recreational stock. Through adverse effects on plant vigor, both grazing and trampling can reduce vegetative cover. Loss of cover, along with the selective preference of grazing animals for certain species, as well as selective resistance to both trampling and grazing pressures, leads to changes in species composition. Native colonizer species may increase in importance or, as is often the case, alien species brought in as seed in feces, on coats or hooves, or in supplemental feed, may proliferate. Such changes represent substantial alteration of natural conditions.

Most recreational impacts in wilderness (on trails and campsites, for example) affect only a small proportion of any ecosystem type. 
In certain wilderness areas, however, some meadow and grassland types are limited in occurrence, and packstock grazing is widely dispersed. In these places, packstock grazing can alter vegetation types over their entire range, severely reducing the scientific value of wilderness as a provider of representative examples of unaltered ecosystems. Concern over this potential outcome led Sequoia and Kings Canyon National Parks to establish a network of representative examples of each meadow association to be protected from stock use (DeBenedetti and Parsons 1983).

Pronounced loss of cover and shifts in composition toward less palatable species reduce available forage. This creates problems of inadequate forage for stock users and can result in competition with native wildlife, although we have little idea how common or serious this is. Trampling can also break down streambanks and destabilize drainage networks. In severe cases it can lead to the disintegration of sod and accelerated erosion (DeBenedetti and Parsons 1979).

In addition to having only a rudimentary knowledge about the impacts of stock use, we know little about the importance of factors that influence amount of impact. Clearly, the timing, frequency, periodicity, and intensity of grazing are important. So are environmental variables such as the resistance of constituent species and edaphic characteristics. Moreover, vulnerability varies seasonally with both the carbohydrate storage cycle of individual species and with environmental characteristics, particularly soil moisture. All of these factors are subject to varying degrees of control, either through establishment of management programs or through alteration of the behavior of stock users. If we had a better understanding of the importance of these factors and how they could be manipulated to minimize disturbance, problems could be kept to a minimum.

Three lines of research that could contribute substantially to our ability to manage recreational stock in wilderness are:

(1) Conduct a literature review and problem analysis. There is a voluminous literature and considerable body of expertise in range management, even if little research has been conducted in wilderness. This knowledge could be tapped to identify probable significant impacts, improve predictive capabilities regarding factors that influence amount of impact, and suggest effective management strategies and low-impact behaviors. From such a conceptual analysis, it should be possible to identify major research gaps and productive avenues of research.

(2) Analyze the effects of amount, timing, and frequency of use on different vegetation types. Several stock management strategies involve limiting numbers of stock and the temporal and/or spatial distribution of stock use. For such strategies to be effective, we need to be able to predict how manipulation of these factors will affect vegetation and soils. Although analysis of backcountry range can offer some insights, careful experimentation is probably the most efficient way to isolate the effects of individual variables.

(3) Analyze the effects of alternative means of constraining and grazing stock. Stock can be constrained in a number of ways, including use of hobbles, pickets, hitch lines, and corrals. Each technique differs in its potential for causing ecological impact. If pickets are used, frequency of rotation has an important influence on impact. The provision of supplemental feed is also capable of reducing certain impacts. We need a better understanding of the advantages and disadvantages of these alternative techniques. Again, experimentation in a variety of use and environmental situations is needed.

Other productive research topics include an evaluation of the severity of competition between stock and wildlife, a better understanding of the grazing behavior of horses and mules, and a better perspective on the significance of recreational stock impacts in relation to varied wilderness values.

\section{Domestic Livestock in Wilderness}

Although seldom documented, the effects of domestic livestock, usually cattle and sheep, have been pronounced in many wildernesses, particularly in the West (Reid and others 1980, Vale 1977, Vankat and Major 1978). Many areas supported huge herds in the late 19th and early 20th centuries. Although the largest herds were reduced dramatically following recognition of unacceptable levels of deterioration, grazing of livestock still has a substantial impact on wilderness ecosystems.

Although there is an extensive literature on livestock grazing, vegetation, and soils, most of it is prescriptive and does not apply directly to wilderness situations. Most prescriptions relate to objectives aimed at maximizing sustained production, with little importance attached to "naturalness" for its own sake. Because there is a paucity of quantitative data on how vegetation and soil characteristics on public lands have been altered by grazing (Branson and Miller 1981), it is difficult to evaluate with much precision the significance of current grazing or to suggest management prescriptions that optimize both production and naturalness.

This suggests three basic lines of needed research:

(1) Conduct a literature review and problem analysis. We need to define variables and develop standards for evaluating "naturalness." Certain grazing effects, such as accelerated erosion, conflict with both naturalness and sustained production goals. Other effects, such as a shift in species composition toward more productive species, conflict with naturalness goals, but not production or range condition goals. A review could evaluate the similarities and disparities between management for these various goals and suggest ways in which naturalness could be enhanced without unacceptable impact on grazing operations. High-priority research gaps related to livestock impacts, the factors that influence amount of impact, and potential mitigation measures could also be identified.

(2) Analyze the nature and severity of livestock impacts on wilderness vegetation, soil, animals, and water. Although such impacts are obvious, it is difficult to evaluate their significance or prevalence. Many of the less obvious impacts have probably not even been identified. The nature and severity of impact undoubtedly vary greatly from deserts of the Southwest, where water bodies and cryptogamic soils are particular concerns, to high mountains or less fragile environments. This research should involve both analysis of grazed areas and experimentation in a variety of wilderness ecosystems.

(3) Develop management prescriptions designed to optimize both production and naturalness. Based on information about the effects of grazing on vegetation and soil, develop strategies that include a concern for maintenance of natural conditions. In wilderness, this goal is added to the more traditional goals of maintaining range condition and sustained production. Potential strategies could be tried in places and monitored to evaluate effectiveness. This research could be designed in a manner similar to many range projects by merely shifting evaluative standards to reflect a new concern for maintenance of natural conditions.

\section{Conclusion}

Our ability to manage wilderness has not kept up with our interest in designating wilderness. There is much we need to learn before we can effectively manage wilderness, particularly given the inherent conflict between use and preservation built into enabling legislation. We have limited knowledge about the impacts of domestic and recreational livestock and how such impacts might be managed. Livestock have a particularly high potential for disrupting natural ecosystems and they are often spread over relatively rare ecosystem types; consequently, they are a critical con- 
cern. Range science has made contributions to effective management of public lands. As more of our public lands are devoted to the objectives of wilderness, we must shift our research to provide answers to the new questions being asked by public land managers.

\section{Literature Cited}

Branson, R., and R. Miller. 1981. Effects of increased precipitation and grazing management on northeastern Montana rangelands. J. Range Manage. 34:3-10.

Cole, D.N. 1983. Campsite conditions in the Bob Marshall Wilderness, Montana. USDA Forest Serv. Res. Pap. INT-312, Ogden, Utah.

Dale, D., and T. Weaver. 1974. Trampling effects on vegetation of the trail corridors of north Rocky Mountain forests. J. Appl. Ecol. 11:767-772.

DeBenedetti, S.H., and D.J. Parsons. 1979. Mountain meadow management and research in Sequoia and Kings Canyon National Parks: a review and update. p. 1305-1311. In: R. Linn (ed.). Proc. First Conference on Scientific Research in the National Parks. USDI National Park Service Trans. and Proc. Series No. 5. Washington, DC. Vol. II.
DeBenedetti, S.H., and D.J. Parcons. 1983. Protecting mountain meadows: a grazing management plan. Parks 8:11-13.

Lucas, R.C. 1985. Visitor characteristics, attitudes and use patterns in the Bob Marshall Wilderness complex, 1970-82. USDA Forest Serv. Res. Pap. INT-345, Ogden, Utah.

McQuaid-Cook, J. 1978. Effects of hikers and horses on mountain trails. J. Environ. Manage. 6:209-212.

Reid, E.H., G.S. Strickler, and W.B. Hall. 1980. Green fescue grassland: 40 years of secondary succession. USDA Forest Serv. Res. Pap. PNW-274, Portland, Ore.

Vale, T.R. 1977. Forest changes in the Warner Mountains, California. Ann. Assoc. Amer. Geogr. 67:28-45.

Vankat, J.L., and J. Major. 1978. Vegetation changes in Sequoia National Park, California. J. Biogeogr. 5:377-402.

Weaver T., and D. Dale. 1978. Trampling effects of hikers, motorcycles, and horses in meadows and forests. J. Appl. Ecol. 15:451-457.

Whittaker, P.L. 1978. Comparison of surface impact by hiking and horseback riding in the Great Smoky Mountains National Park. USDI National Park Serv., Southeast Region, Manage. Rep. 24, Atlanta, Georgia. 